\title{
Periádica Eletrânica

\section{O AVANÇO DA MANCHA URBANA DE PATROCÍNIO (MG) SOBRE MANANCIAIS COM POTENCIAL DE ABASTECIMENTO URBANO*}

\author{
Renato Emanuel Silva ${ }^{1}$ \\ Washington Luiz Assunção ${ }^{2}$
}

\begin{abstract}
RESUMO
É objetivo do presente trabalho avaliar o avanço da mancha urbana de Patrocínio (MG) sobre a bacia do rio Dourados. O estudo de caso proposto reflete sobre os impactos que o processo de urbanização pode gerar em uma bacia hidrográfica. Assim foram realizadas atividades de campo para conhecer a realidade da bacia de estudo na área de contato entre rural e urbano. Foi produzido um mapa que apresenta a situação atual de urbanização e a expectativa do avanço urbano sobre os setores rurais da bacia. A maior parte da bacia encontra-se com aspectos rurais. Contudo e claro o avanço urbano na porção oeste gerando impactos como retirada da vegetação, picos de escoamento superficial, impermeabilização do solo e aumento das erosões. Os resultados revelam a necessidade de um gerenciamento ambiental na área para que o avanço urbano não seja realizado de modo a prejudicar os mananciais e que o escoamento superficial seja contido para evitar grandes cheias e formas erosivas.
\end{abstract}

PALAVRAS-CHAVE: urbanização, recursos hídricos, impactos ambientais

\section{ADVANCING THE STAIN URBAN SPONSORSHIP (MG) ON FISH STOCK WITH POTENTIAL SUPPLY URBAN}

\begin{abstract}
It is the aim of this study evaluate the progress of urban sprawl Patrocínio (MG) on the Dourados river basin. The study proposed case reflects on the impact that the process of urbanization can generate in a watershed. Were carried out field activities to know the reality of the study basin in the contact area between rural and urban. A map showing the current situation of urbanization and the expectation of urban improvement over the rural sectors of the basin was produced. The major part of the basin is in rural aspects. The aspects Urban in the western portion generating impacts such as removal of vegetation, runoff peaks, soil sealing and increased erosion. The results reveal the need for environmental management in the area for the urban progress is not made in order to damage the springs and runoff is contained to prevent major floods and erosive forms.
\end{abstract}

KEYWORDS: urbanization, water resources, environmental impacts

\footnotetext{
${ }_{1}^{1}$ Mestre em Planejamento Ambiental, IG/UFU - renato.logan@gmail.com

${ }^{2}$ Doutor em Geografia, IG/UFU. E-mail.wlassuncao@gmail.com
} 


\title{
AVANZANDO EL PATROCINIO MANCHA URBANA (MG) SOBRE LAS POBLACIONES DE PECES CON SUMINISTRO DE POTENCIAL URBANO
}

\begin{abstract}
RESUMEN
Es el objetivo de este estudio fue evaluar el progreso de Patrocinio expansión urbana (MG) en la cuenca del río Dourados. El caso de estudio propuesto refleja en el impacto que el proceso de urbanización puede generar en una cuenca hidrográfica. Así que se llevaron a cabo actividades de campo para conocer la realidad de la cuenca de estudio en el área de contacto entre zonas rurales y urbanas. Se elaboró un mapa que muestra la situación actual de la urbanización y la expectativa de mejora urbana en los sectores rurales de la cuenca. La mayor parte de la cuenca es en aspectos rurales. Urbano hacia adelante con todo y por supuesto en la porción occidental generando impactos tales como la eliminación de la vegetación, picos de escorrentía, el sellado del suelo y el aumento de la erosión. Los resultados ponen de manifiesto la necesidad de la gestión ambiental en el área para el progreso urbano no se hace con el fin de dañar los manantiales y aguas de escorrentía se contiene para evitar grandes inundaciones y formas erosivas.
\end{abstract}

PALABRAS CLAVE: urbanización, recursos hídricos, impactos ambientales

\section{INTRODUÇÃO}

No Brasil a expansão de áreas urbanas e a modernização do meio rural são geralmente marcadas pelos conflitos com questões ambientais. No meio rural o estabelecimento de commodities, voltadas ao atendimento do agronegócio, gera um grande consumo de água, além dos impactos relativos a contaminação ou supressão de mananciais (Tundisi e Tundisi, 2011). A queda da quantidade e qualidade da água prejudica os ecossistemas aquáticos. Também ocorrem conflitos pela água uma vez que as demandas de consumo, muitas vezes, superam a disponibilidade existente, um atestado da falha ou ausência da gestão do recurso como sugerem MOURA et al, 2008 bem como Cruz e Tucci (2001).

Já a urbanização sobre bacias hidrográficas, gera problemas como impermeabilização do solo, supressão de nascentes, intervenções em canais, episódios de cheia entre outros exemplos encontrados neste processo (Guerra, 2011). Também existe a contaminação de mananciais por lançamento de efluentes e problemas relativos ao aumento da carga de sedimentos e lixo motivada pelas cheias urbanas (Tucci e Mendes, 2006).

O potencial do consumo hídrico urbano também precisa ser levado em consideração. Residências, comércios, clubes, indústrias, órgãos públicos são alguns dos ambientes que demandam abastecimento para atender as populações. 


\section{Periódica Eletranica

Não são raros os casos em que o avanço urbano ocorre sobre bacias que poderiam fornecer água para o atendimento destas demandas.

A geração de danos aos mananciais tem um efeito ainda maior, nas áreas de transição entre o rural e urbano. Nas bordas das cidades são comuns depósitos irregulares de lixo e entulhos oriundos da construção civil. Também o esgoto, quando não tratado, contamina cursos fluviais, lagos e reservas subterrâneas. As erosões se tornam ainda mais evidentes por conta do fluxo superficial que se concentra nas ruas pavimentadas e atinge as áreas rurais gerando feições erosivas.

Sendo importante que o desenvolvimento urbano seja baseado na ótica do planejamento ambiental de modo que os territórios a serem apropriados sofram os menores impactos possíveis (Santos, 2004). Assim é fundamental que a abertura de novas áreas urbanas sejam condicionadas a avaliação de especialistas e que se procure restringir as áreas impactadas. Contudo a falta de um planejamento e do envolvimento de profissionais como geógrafos, arquitetos, engenheiros entre outros profissionais (Girão e Correia,2004) especializados na compreensão das relações do homem com o meio, gera cenários extremamente problemáticos.

Um caso exemplar é a realidade do avanço urbano de Patrocínio (MG), onde a falta de organização e de gerenciamento competente levou a cidade a ocupar três bacias hidrográficas distintas. Investigar a condição que se encontra o avanço urbano é importante uma vez que revela o significado destes impactos sobre uma bacia hidrográfica, principalmente no que se refere à preservação dos mananciais e mudanças na condição do solo sobre o escoamento superficial e a infiltração de água.

Para o presente artigo a área de estudo compreende a bacia do Alto Curso do Rio Dourados, inserida em uma área de transição entre a cidade de Patrocínio-

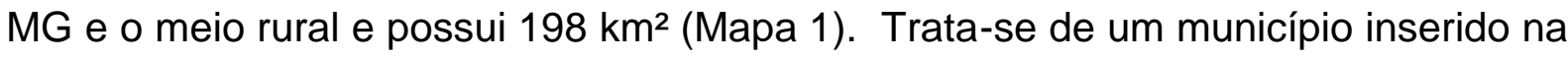
mesorregião do Triangulo Mineiro, A bacia não possuía ocupações urbanas significativas até meados dos anos de 1980. A partir desse período a modernização rural incidiu sobre o meio urbano potencializando seu crescimento. A cidade que ocupava a bacia do córrego Rangel, passou a avançar também para as bacias do córrego Congonhas e da região das nascentes do rio Dourados que é alvo desta pesquisa. 
Mapa 1:Localização da área de estudo.

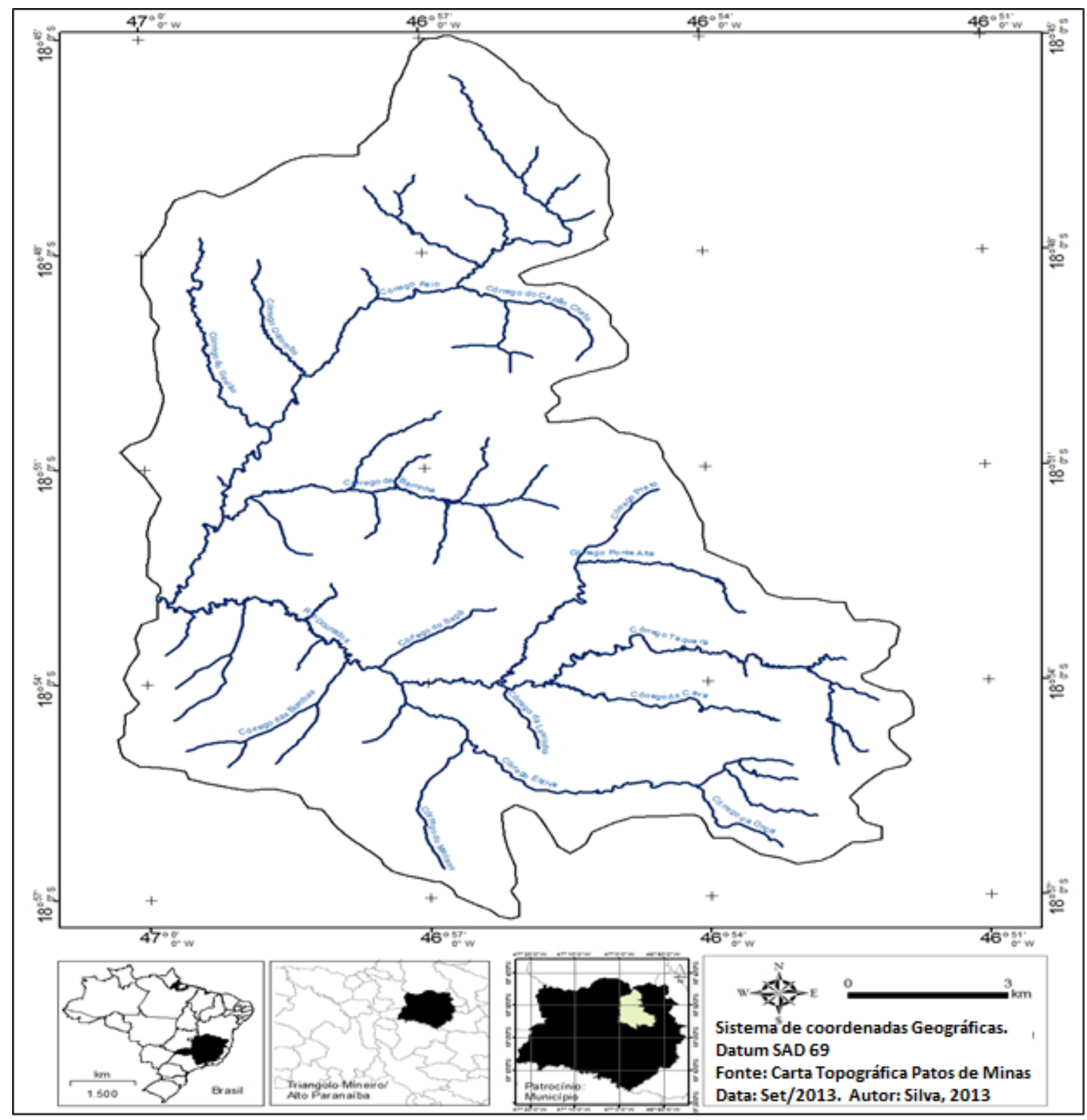

A área encontra-se na transição entre litologias dos grupos Canastra e Bambuí, o relevo é predominantemente suavizado, à exceção das vertentes íngremes das Serras do Cruzeiro, Gavião, Chapadão Coromandel e Domo de Serra Negras, todas funcionando como divisores de água da bacia (Machado, 2002). Os solos, segundo Matos (2005), são predominantemente latossolos, embora litossolos, 
cambissolos e gleissolos podem ser encontrados em algumas manchas. O clima é tropical com estação chuvosa no verão e inverno seco (Mendes, 2008).

\section{OBJETIVO}

É objetivo do presente trabalho avaliar o avanço da mancha urbana de Patrocínio (MG) sobre a bacia do rio Dourados, portadora de potencial para atender futuras demandas hídricas.

\section{MATERIAIS E MÉTODOS}

Para conhecer a condição do avanço da mancha urbana de Patrocínio (MG) sobre a bacia do alto curso do Rio Dourados se tornou necessário o levantamento sobre o histórico de ocupação da região, por meio de registros históricos e contribuição de moradores das áreas. Também a avaliação de imagens da série Landsat entre 1985 e 1990 permitiu observar o inicio da apropriação urbana destas áreas. Paralelamente a esta fase também ocorreram consultas a autores sobre questões urbanas, impacto ambiental urbano e planejamento ambiental, de modo especial em bacias hidrográficas.

As atividades de campo foram realizadas em três etapas:

- Limites entre rural e urbano (03/2013)

- Interior dos bairros consolidados e zonas de expansão urbana (04/2013)

- Meio rural com potencialidade para expansão urbana e com loteamento (07/2013)

Nesta etapa identificaram-se impactos como retirada de vegetação, impermeabilização ou remoção do solo, formação de processos erosivos, além de lançamento de esgoto em cursos fluviais. Para arquivamento foram realizadas fotografias das áreas visitadas.

Em ambiente SIG foram verificados quais setores da cidade de Patrocínio estão inseridos na bacia de estudo, assim como foram traçados cenários futuros da expansão urbana, levando em consideração a topografia do terreno, Áreas de 


\section{Periádica Eletranica

Preservação Permanente e setores rurais que estejam sem atividade agrícola condizente com seu potencial econômico sugerindo passividade ao avanço urbano.

O setor urbano consolidado, aqueles em expansão e as áreas potencialmente susceptíveis ao crescimento urbano foram demarcados e espacializados por meio do Software Arc Gis 10.1. Para tanto foram utilizadas imagens do sensor BlackBridge (RapidEye) do ano de 2010, sendo necessários os campos para atualização de dados relativos a ocupação da bacia.

Quanto ao tratamento de imagens, os produtos dos sensores Lansat foram registrados no SPRING 5.2.3 e referenciadas na carta topográfica Patos de Minas do IBGE na escala de 1:100.000. Também foi realizado contraste no SPRING, via equalização do histograma, e formado um mosaico com estas imagens. Deste modo foi possível identificar a presença de elementos urbanos distintos das demais modalidades de uso e ocupação do solo. Para o mapeamento urbano recente, ou seja as áreas ocupadas pela cidade de Patrocínio dentro da bacia, e a realização das projeções futuras foram utilizadas imagens do sensor BlackBrigde 2010 (com a composição colorida BGR para as bandas Red - (630 á $690 \mu \mathrm{m}$ ), Green (520 á 590 $\mu \mathrm{m})$; Near IR $(0,76-1,2 \mu \mathrm{m}))$.

Por fim a partir dos dados, obtidos nas etapas de campo e gabinete, foram analisados os impactos, principalmente na dinâmica de uma bacia hidrográfica, partindo das proposições de Tucci e Mendes (2006) para preservação de mananciais e os planos de gestão das vertentes de contribuição.

\section{RESULTADOS}

Muitas cidades localizadas na região central do Brasil se mantiveram desarticuladas, até os anos de 1960, baseadas em atividades arcaicas e ajustadas ao meio rural tradicional. Contudo se seguiram uma série de projetos de desenvolvimento agrícola que orientaram uma nova fase do crescimento urbano. $O$ aumento das áreas urbanas nem sempre foi conciliado às demandas ambientais.

O perímetro urbano, do ponto de vista da avaliação ambiental, permite múltiplas leituras para a dinâmica de uma bacia hidrográfica. Como existem áreas urbanas em diversos estágios de desenvolvimento é necessário pontuar os processos atuais, ou que tiveram maior ocorrência no desenvolvimento urbano. 
A cidade de Patrocínio (MG) foi fundada na bacia do córrego Rangel (mapa 2) contudo a falta de planejamento levou a ocupação de duas outras bacias. Um fragmento urbano foi constituído no córrego Congonhas e outro na região do alto curso do rio Dourados que possui cursos fluviais responsáveis pelo abastecimento urbano de Patrocínio e outros que poderiam fornecer um volume adicional de água, em um cenário de aumento da demanda hídrica.

Ao lidar com as porções urbanas de Patrocínio, inseridas na bacia de estudo, considera-se o período de instalação destes espaços urbanos, os mesmos partem da abertura da vegetação vigente ou conversão do uso pré-existente (foto 1 ). Posteriormente existe um período em que as ruas são traçadas, eventualmente asfaltadas e formados os lotes, ainda sem construções. Em seguida inicia-se o período de fixação dos moradores e estes espaços vão se tornando impermeabilizados. $O$ escoamento superficial ganha volume, assim como o aumento da contaminação dos mananciais. Também as erosões nos limites do bairro se tornam pronunciadas (SANTOS, 2004).

Foto 1: Alto curso da bacia do rio Dourados - Retirada da cobertura do solo para abertura de novo setor do Bairro Serra Negra

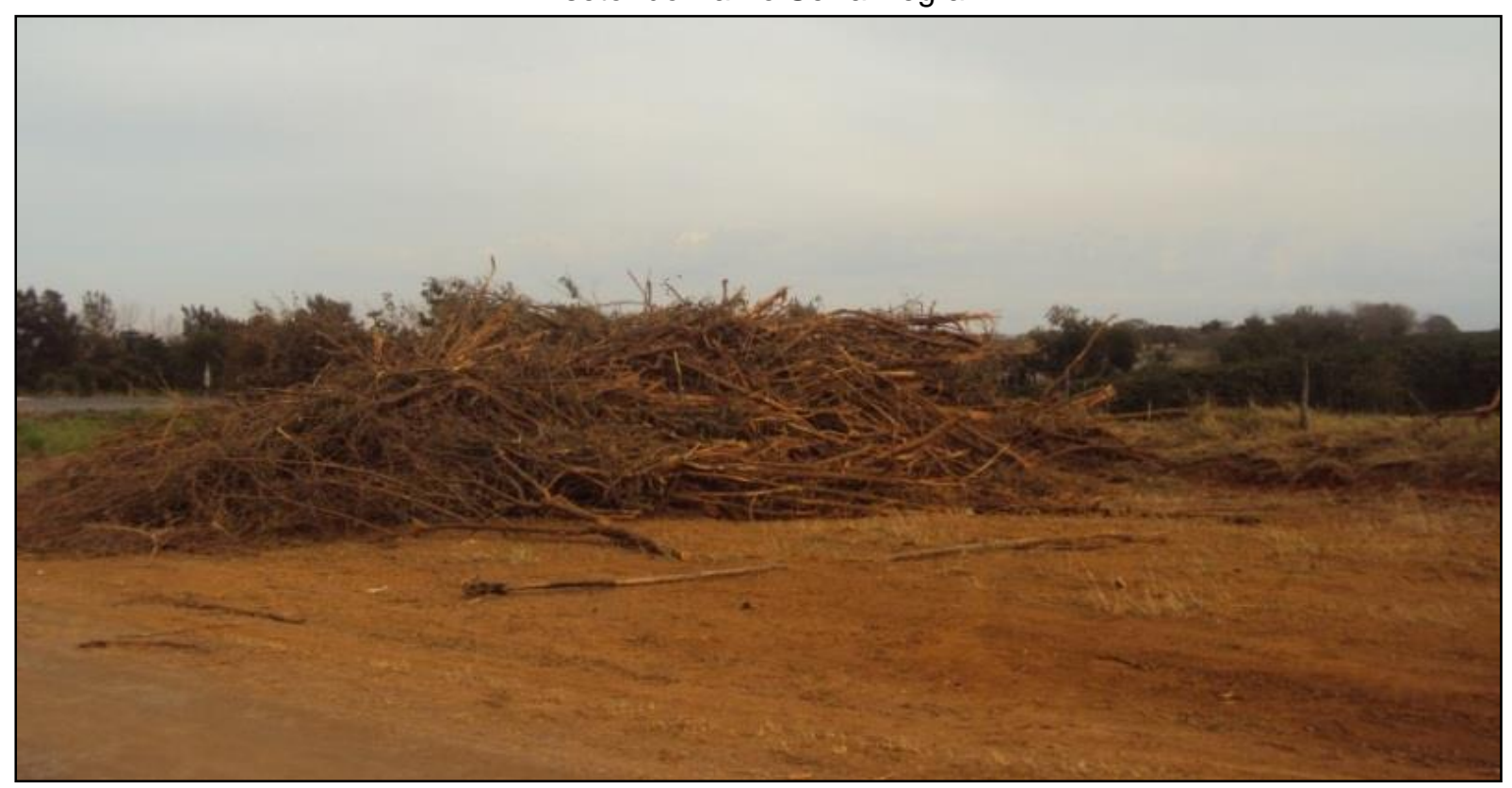

Fonte: Silva (2013) 
Mapa 2 : Setores urbanos de Patrocínio

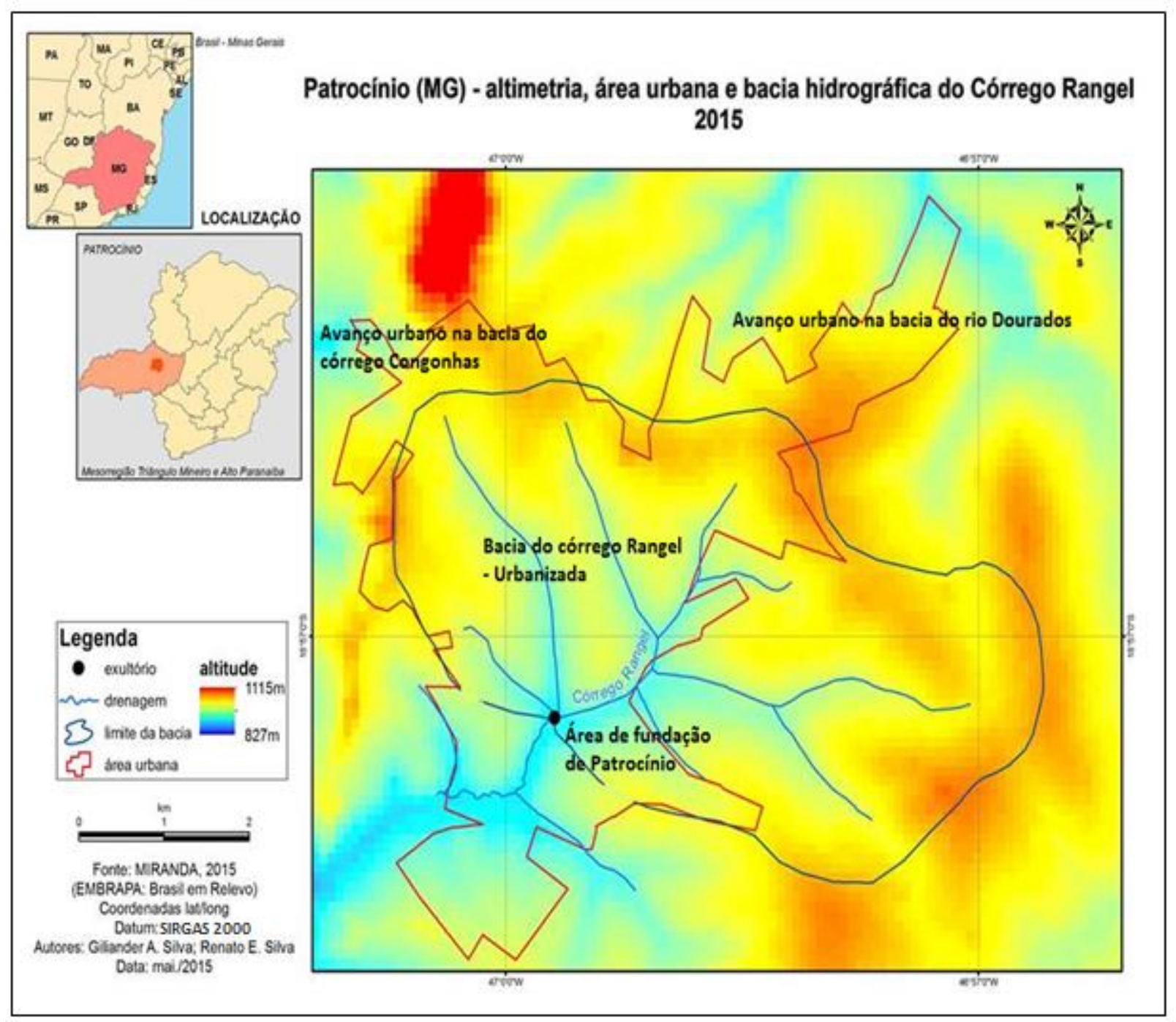

Para o caso da porção sudoeste da bacia do rio Dourados, os últimos 25 anos são testemunhas de uma constante evolução urbana. Existindo hoje diversas fases de desenvolvimento urbano, de bairros já consolidados a aberturas de novos lotes (foto 2). A complexidade dos impactos ambientais urbanos em diversos estágios se dá pela interação dos mesmos sobre a área. 
Foto 2: Alto curso da bacia do rio Dourados: Abertura de novos setores do Bairro Nações

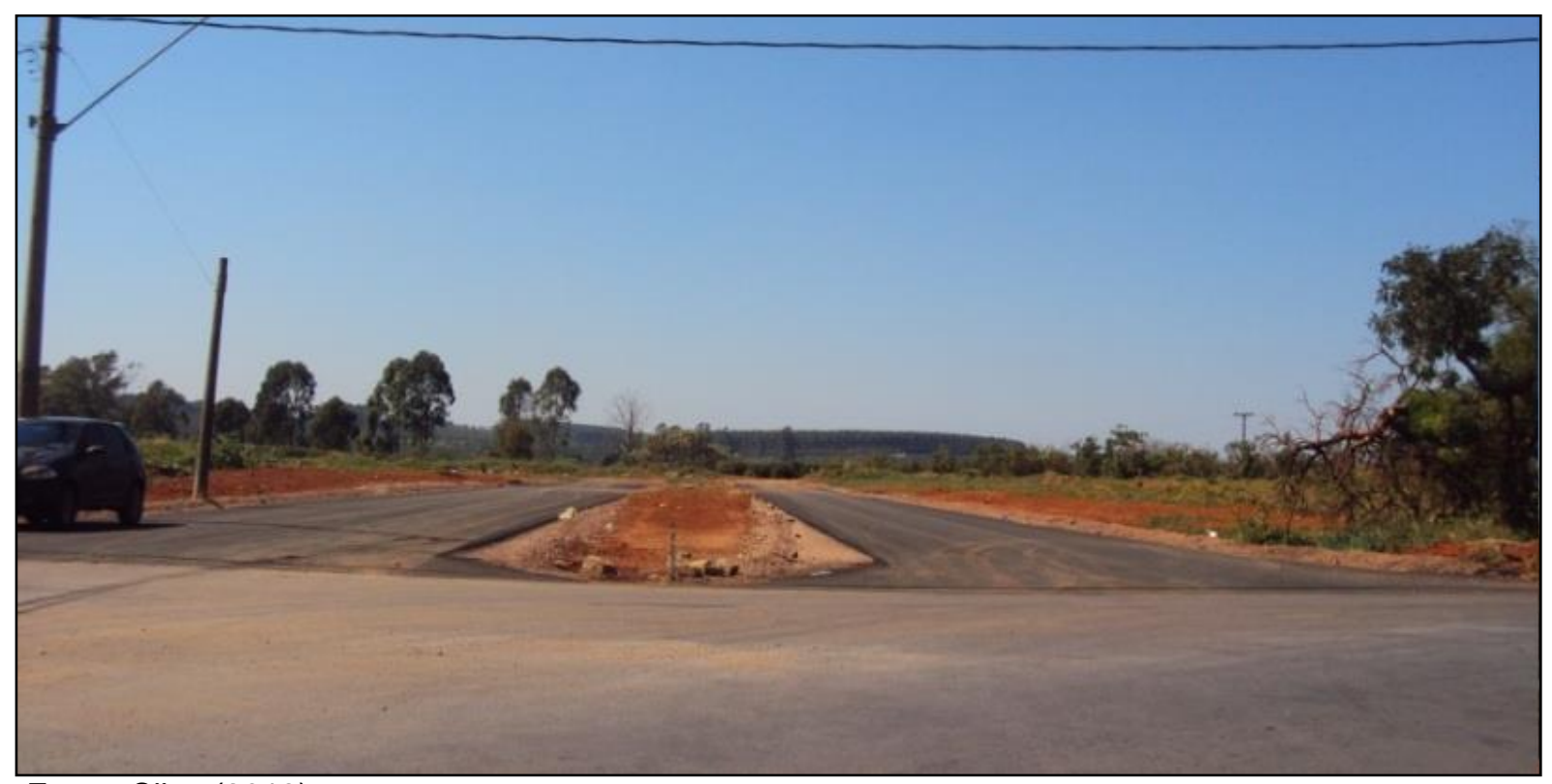

Fonte: Silva (2013)

As erosões, observadas sobretudo nas bordas do bairro Serra Negra, são potencializadas pelo escoamento superficial proveniente das áreas impermeabilizadas, nas palavras de Thomaz et al:

Os barrancos expostos sofrem a ação de salpico e, especialmente, a constantes ciclos de umedecimento e ressecamento, causando contração do material. A expansão-contração provoca o colapso do material sob ação da gravidade. Esse processo é agravado pelo ângulo do barranco ( $90^{\circ}$ ou mais). O material que se desprende do barraco fica depositado na lateral da estrada e é transportado posteriormente pelo escoamento superficial. (THOMAZ et al, 2001, p.31)

tempo de concentração da bacia também sofre alterações a partir da urbanização de alguns setores, pela supressão de áreas vegetadas, impermeabilização do solo e queda da recarga do lençol freático.

Durante o desenvolvimento urbano, o aumento dos sedimentos produzidos pela bacia hidrográfica é significativo, devido às construção de ruas, avenidas e rodovias entre outras causas. As principais consequências ambientais da produção de sedimentos são as seguintes: (a) assoreamento das seções da drenagem, com redução da capacidade de escoamento de condutos, rios e lagos urbanos. (b) transporte de poluente agregado ao sedimento, que contaminam as águas pluviais. À medida que a bacia é urbanizada, e a densificação é consolidada, a produção de sedimentos pode reduzir. (TUCCI; MENDES, 2006, p.26) 
O lixo e o entulho constituem sério problema, sendo catalizadores de doenças, como aquelas propagadas por pragas. É comum encontrar lixo em terrenos não ocupados e principalmente nas bordas dos bairros e nos mananciais. A contaminação dos mananciais e da água subterrânea também é uma consequência grave da apropriação urbana. Esta deterioração da qualidade da água surge a partir da lavagem das superfícies como casas, ruas e outros aparatos urbanos, a ligação clandestina de esgoto em redes pluviais e o despejo de resíduos contaminados em áreas não preparadas.

Cabe em última análise a projeção do crescimento urbano na área de estudo para tanto, foram levantadas as áreas urbanas consolidadas, aquelas que estão recebendo estruturação (foto 3 ), setores com venda de lotes (mas sem alteração significativa da paisagem) e por fim áreas que segundo o plano municipal de crescimento urbano, são consideradas aptas para urbanização futura e que atualmente não apresentam qualquer atividade rural, sugerindo uma alta susceptibilidade ao avanço urbano (mapa 3).

Foto 3: Alto curso da bacia do rio Dourados: Abertura de bairro na cabeceira do córrego das Bombas. $\mathrm{Na}$ imagem a abertura de ruas e inserção de manilhas respondem pela nova realidade da área, antes uma lavoura temporária, agora sofrendo o processo de urbanização.

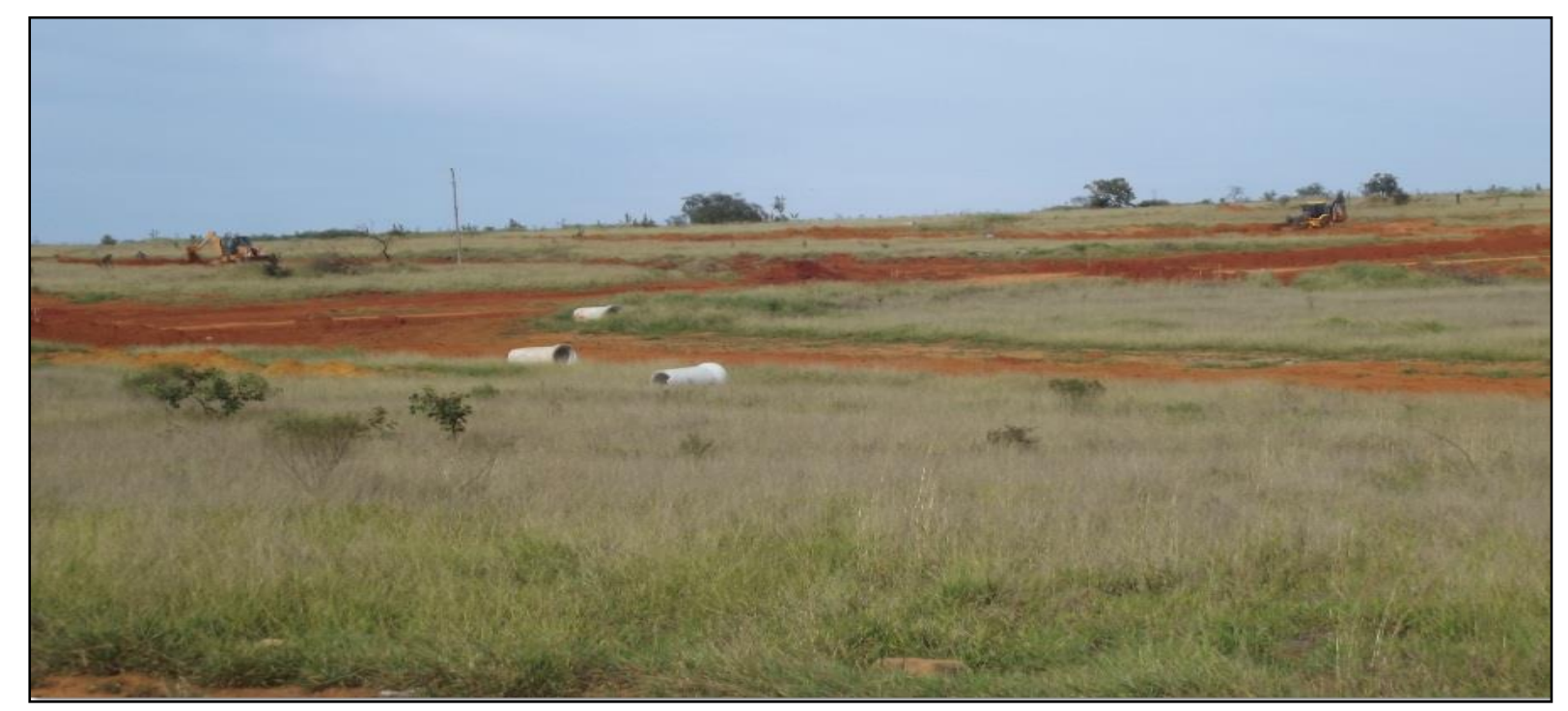

Fonte: Mendes (2013) 


\section{Fórum Ambiental}

da Alta Paulista

Volume 11, Número 06, 2015

Mapa 3: Urbanização atual e projeção para a bacia do alto curso do rio Dourados

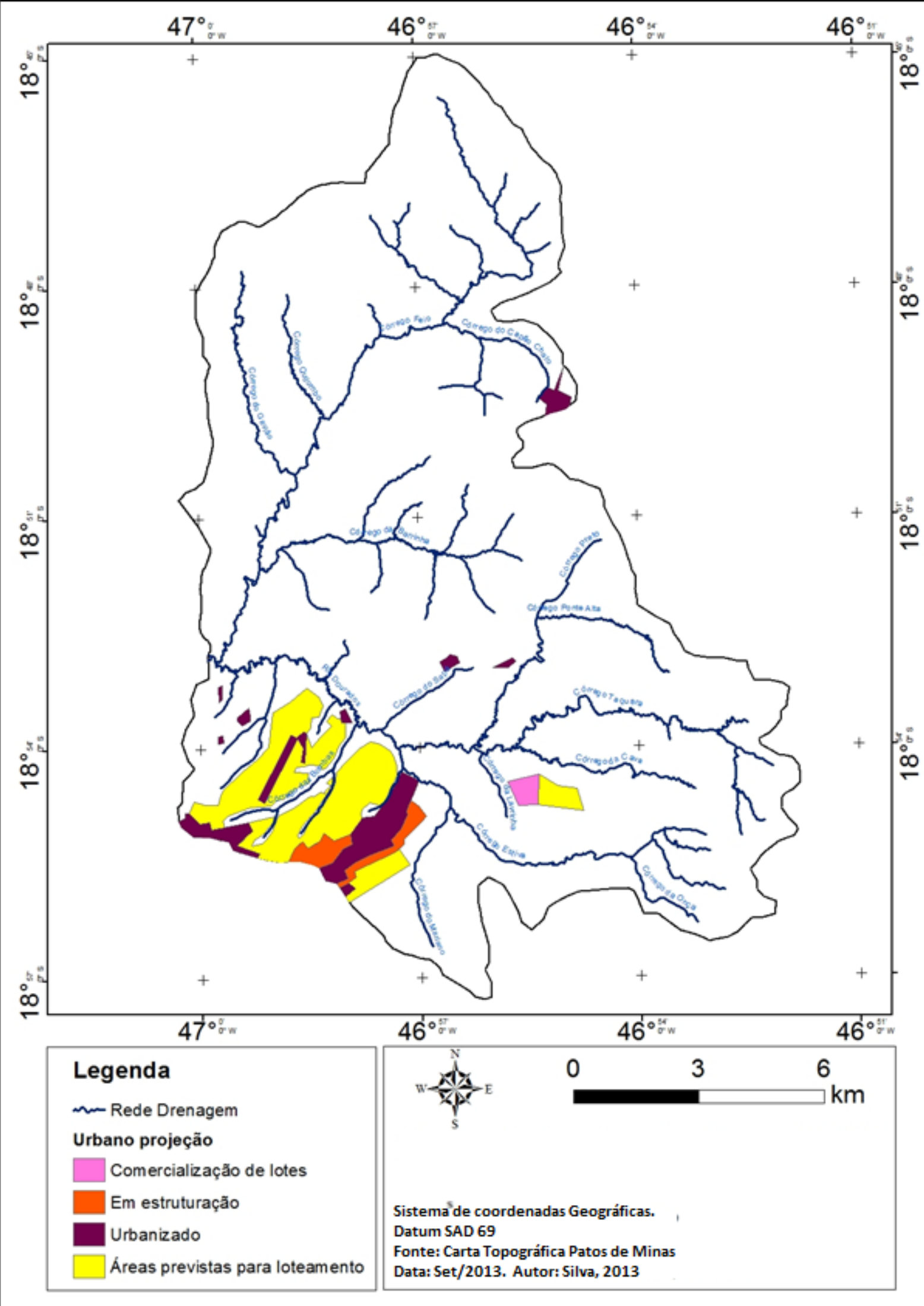


A cidade de Patrocínio possui $19,6 \mathrm{~km}^{2}$ de área edificada, destes $4,5 \mathrm{~km}^{2}$ estão dentro da bacia de estudo, ocupando $2,31 \%$ do total de sua área. As obras em curso levarão ao aumento de mais $1,3 \mathrm{~km}^{2}$, já as áreas que podem ser ocupadas por bairros são $9,43 \mathrm{~km}^{2}$. Estes novos espaços sofrendo ocupação total ou parcial representam o agravamento das condições aqui discutidas, e exigem um olhar cuidadoso por parte dos órgãos envolvidos em tais projetos. Os loteamentos na borda da bacia podem provocar picos de vazão e contaminação de mananciais (tabela 1).

Tabela 1: Condição atual e projeção da urbanização para o alto curso da BHRD.

\begin{tabular}{ccc}
\hline Condição da área & dimensão da área $\left.\mathbf{( k m}^{2}\right)$ & Área total (\%) \\
\hline Área urbana estabelecida & 4,5 & 2,31 \\
Em estruturação & 1,3 & 0,7 \\
Divulgação e venda de lotes & 0,42 & 0,22 \\
Previsto para loteamento & 9,43 & 4,9 \\
\hline
\end{tabular}

Fonte: PMP/SILVA, 2013.

As presenças de loteamentos próximos ao córrego da Lavrinha preocupam também pela questão da contaminação das águas subterrâneas, pois o empreendimento está longe das estações de tratamento urbano e a possibilidade da instalação de fossas negras pode comprometer ainda mais a qualidade dos recursos hídricos subterrâneos naquele setor. Também posteriores processos de pavimentação das ruas podem causar eventos de cheia até então inexistentes na área, além da problematização causada pela impermeabilização de vias e lotes que responderá pela diminuição da recarga das reservas hídricas subterrâneas.

Chama atenção o fato desta não ser uma área ambientada dentro dos limites de expansão do perímetro urbano, tendo sido lançada como chácaras urbanas. Nesta direção, também um novo loteamento tem sido planejado na área, além de uma construção iniciada junto ao córrego Taquara referente a fragmentação de antigas propriedades rurais. Se esta tendência se consolidar, é possível que este setor rural, correspondente as nascentes do rio Dourados, marcada por grande numero de córregos e canais artificiais, venha a se urbanizar. Tal resolução elevaria os problemas e causaria ainda uma demanda de planejamento urbano novo. 


\section{Periódica Eletrânica

\section{CONSIDERAÇÕES FINAIS}

O avanço da cidade de Patrocínio, apresentado nesta pesquisa, revela a fragilidade das áreas de contato em rural e urbano. Nestes locais a inserção de novas áreas urbanizadas causa o aumento de problemas relativos a erosão, contaminação do solo e mananciais, além dos eventos de cheia urbana e da impermeabilização do solo.

É fundamental que os órgãos voltados ao planejamento urbano e a conservação ambiental do município orientem processos de ocupação que respeitam e legislação ambiental, e que não permitam a supressão de áreas verdes e as intervenções nos fundos de vale. As áreas ainda não apropriadas, mas que estejam vocacionadas a esta realidade, necessitam de meios para reter os fluxos superficiais de água, bem como direcionar os efluentes produzidos para estações de tratamento de esgoto. Assim o avanço das áreas urbanas deve ser planejado, buscando diminuir os impactos sobre áreas cursos fluviais. Tal dinâmica deve responder pelo aumento da qualidade da água nos cursos fluviais, queda nas enchentes, diminuição de problemas erosivos em canais fluviais e adjacências. Melhorias estas que beneficiariam tanto as comunidades humanas envolvidas quanto as interações ecossistêmicas existentes.

\section{REFERÊNCIAS}

CRUZ, J.C.; TUCCI, C.E.M. Disponibilidade Hídrica para Outorga: Avaliação de aspectos técnicos e conceituais. Programa de Pós Graduação Engenharia de Recursos Hídricos e Saneamento Ambeintal. UFRGS, 2001

MACHADO, M.D.G. As unidades morfológicas e a estruturação da paisagem no município de Patrocínio - MG. Uberlândia: UFU, 2001. (Dissertação de Mestrado).

MATOS, A.T. et al. Alteração de atributos químicos no solo de rampas utilizadas no tratamento de águas residuárias. Revista Brasileira de Engenharia Agrícola e Ambiental. Campina Grande. v.9, n.3. p, 406-412, 2005

MENDES P.C. et Al Análise Climática e suas influências na Cultura Cafeeira no Minicípio De Patrocínio-MG. Uberlândia: UFU, 2008

MOURA, E.M. et al. Avaliação da disponibilidade hídrica e da Demanda hídrica no trecho do Rio Piranhas-Açu. RBRH-Revista Brasileira de Recursos Hídricos 2008 
SANTOS, R.F. Planejamento Ambiental: teoria e prática. São Paulo: Oficina de Textos, 2004.

TOMAZ, P. Cálculos hidrológicos e hidráulicos para obras municipais. São Paulo: Ed.Navegar. 2002

TUCCI, C.E.M.; MENDES, C.A. Curso de Avaliação Ambiental Integrada de Bacia. Brasília - DF: RHAMA. 2006

TUNDISI,J.G; TUNDISI, T.M-T. Recursos hídricos no Século XXI, São Paulo: Oficina de Textos, 2011 